\title{
Extraperitoneal laparoscopy for para-aortic lymphadenectomy in endometrial carcinoma staging: an approach with higher efficiency
}

Wei Zhang, Lingfang Xia, Xiaotian Han, Xingzhu Ju, Xiaohua Wu and Xiaojun Chen*

\begin{abstract}
Background: Removing more inframesenteric nodes is not only significantly increases the likelihood of finding metastasis for endometrial cancer, but also can add survival advantage. As most patients diagnosed with endometrial cancer are overweight or obesity, a high efficiency approach is important. Aim of this study was to compare the surgical outcomes of extraperitoneal laparoscopic, transperitoneal laparoscopic, and laparotomic para-aortic lymphadenectomy in endometrial carcinoma staging.
\end{abstract}

Methods: We retrospectively reviewed data of all patients diagnosed with primary endometrial carcinoma who were treated at the Department of Gynecologic Oncology, Fudan University Shanghai Cancer Center from 1 January 2017 to 31 December 2019. The numbers of para-aortic lymph nodes, surgical time, complications, blood loss and hospital stay were compared. The patients' medical records and pathological reports were carefully reviewed. Statistical significance was defined as $p<0.05$.

Results: We retrospectively compared patients who underwent extraperitoneal laparoscopy (Group $E, n=20$ ), transperitoneal laparoscopy (group $T, n=21$ ), and laparotomy (group $L, n=135$ ). The median number of para-aortic lymph nodes was significantly higher in group $E$ than in groups $T$ and $L(9.5,5$, and 6 , respectively; $p=0.004$ and 0.0004 , respectively). All patients in group $\mathrm{E}$ underwent successfully dissection to the renal vessel level. The median operation time was significantly shorter in group $L$ than in groups $T$ and $E(94,174$, and 233 min, respectively; $p<$ 0.0001). The median estimated blood loss volume was higher in group $L$ than in groups $T$ and $E(200,100$, and 142.5 $\mathrm{ml}$, respectively; all comparisons $p<0.001$ ), and the length of hospital stay was significantly longer in group $L$ than in Groups T and E $(6,5$, and 6 days, respectively; all comparisons $p<0.001)$.

Conclusion: The extraperitoneal laparoscopic approach for staging endometrial carcinoma harvested higher numbers of para-aortic lymph nodes which could be considered for endometrial carcinoma staging, especially for paraaortic lymph node harvest.

Keywords: Endometrial carcinoma, Extraperitoneal, Transperitoneal, Laparotomy, Minimally invasive, Lymphadenectomy

*Correspondence: xiaojunchen2009@sina.com Department of Gynecologic Oncology, Fudan University Shanghai Cancer Center, Shanghai, China

\section{Background}

Transperitoneal laparoscopic lymphadenectomy was first reported in the early 1990s for surgical staging [1]. As confirmed by the Gynecologic Oncology Group (GOG), the transperitoneal laparoscopic approach is a satisfactory method for surgical staging of endometrial carcinoma [2]. The extraperitoneal approach was first 
reported in 1995 and was primarily used to evaluate para-aortic metastases in patients with cervical cancer [1, $3,4]$; more attention has been given to staging of patients with endometrial cancer via this approach in recent years $[5,6]$. Although laparoscopic surgery is the preferred approach for endometrial cancer, with less blood loss and a shorter length of hospital stay [7], minimally invasive approaches were reportedly used by only $60 \%$ of the gynecological oncologists [8].

Computed tomography, magnetic resonance imaging (MRI) and positron-emission tomography (PET-CT) were used for evaluation of lymph node status. The positive predictive value (PPV) and negative predictive value (NPV) of MRI in detecting lymph node metastasis have been reported to be 47.1 to $78 \%$, and 57 to $94.4 \%$, respectively [9]. For PET-CT was with 50\% PPV and 97.4\% NPV [10]. For women with a completely negative PET scan, $12 \%$ had disease spread to nodes along the aorta [11]. According to these results, surgical evaluation of lymph node status is necessary. However, $50 \%$ of the surgeons routinely stopped at the inferior mesenteric artery if lymphadenectomy was needed, and only $11 \%$ reported routinely dissecting nodes to the level of the renal vessels (RVs) [8]. Considering that $77 \%$ of patients with endometrial carcinoma with positive para-aortic lymph nodes have metastases above the inferior mesenteric artery [7], and because as many as $10 \%$ of patients with clinically early endometrial carcinoma have infrarenal node involvement [12]. Turan et al. [12] reported tumor grade, histologic type, and myometrial invasion cannot be used as markers to decide on supramesenteric lymphadenectomy in endometrial cancer; therefore, the upper limit for para-aortic lymphadenectomy must be the left RV. Removing more inframesenteric nodes significantly increases the likelihood of finding cancer metastasis for endometrial cancer [13], and dissecting the infrarenal nodes during staging can add a $10 \%$ survival advantage [14].

The left aortic nodes contain $63 \%$ of all aortic nodes, which makes the left-sided extraperitoneal technique much easier and suitable for lymph node dissection in patients with endometrial cancer $[15,16]$. With its lower risk of intestinal and urinary injury and adhesions, the extraperitoneal technique is considered superior to the transperitoneal approach in both obese and non-obese patients [17]. One study showed that in non-obese patients, the transperitoneal approach was associated with a higher number of harvested lymph nodes [17].

To date, despite the studies published comparing the different lymphadenectomy approaches [7, 18, 19], only a few studies focused on staging of endometrial carcinoma. Our aim was to compare the surgical outcomes including numbers of para-aortic lymph nodes, surgical time, intra- and post-operative complications, blood loss, and hospital stay of systemic staging of endometrial carcinoma via extraperitoneal, transperitoneal laparoscopic, and laparotomic approaches.

\section{Methods}

\section{Patients and inclusion criteria}

We retrospectively collected and reviewed data for all patients diagnosed with primary endometrial carcinoma who were treated at the Department of Gynecologic Oncology, Fudan University Shanghai Cancer Center, from 1 January 2017 to 31 December 2019. This study was conducted until 1 April, 2020. We included data for patients who underwent systemic staging, including para-aortic lymphadenectomy, and excluded patients who did not undergo para-aortic lymphadenectomy. Patients with a synchronous primary ovarian tumor were also excluded. Clinical information, physical examination notes, operation records, and pathology records were carefully reviewed. Tumor stage was classified according to the 2009 International Federation of Gynecology and Obstetrics (FIGO) staging system. Approval to review the patients' medical records and pathological reports was obtained from the institutional review board of Fudan University Shanghai Cancer Center, Shanghai, China (050432-4-1911D). Written informed consent was obtained from all patients. All patients' data were anonymized to avoid patient information identification during or after data collection. Baseline characteristics of these patients in each group including age, BMI, and stage were compared to ensure their balance.

\section{Surgical procedure}

Systemic staging involved hysterectomy, salpingo-oophorectomy, and pelvic and para-aortic lymphadenectomy. Omentectomy was performed in patients with grade 3 primary endometrioid uterine carcinoma and in those with non-endometrioid carcinoma. Radical hysterectomy was performed when the cervix was involved, which was confirmed using magnetic resonance imaging or biopsy. Because the renal vein was routinely used as the upper margin for lymphadenectomy by our team, all node dissections were attempted to the level of the RVs regardless of the approach. For laparoscopic procedures, the aortic and pelvic nodes were put into a plastic specimen bag and was extracted either virginally or through a $15-\mathrm{mm}$ port [1]. Vaginal manipulator was used when hysterectomy was performed.

Surgery was performed in two steps, for transperitoneal and laparotomy group, first hysterectomy and pelvic lymphadenectomy, and then para-aortic lymph node dissection. And for extraperitoneal group, 
para-aortic lymph node dissection was performed first, and then hysterectomy and pelvic lymphadenectomy.

The procedure for extraperitoneal laparoscopic para-aortic lymphadenectomy was performed as previously reported, with simple modifications $[20,21]$. Briefly, a $10-\mathrm{mm}$ incision was made in the umbilicus for constant visual control during development of the extraperitoneal space. Then, to develop the extraperitoneal space, a $15-\mathrm{mm}$ incision was placed 2 $\mathrm{cm}$ superomedially to the anterosuperior iliac spine. Once the peritoneal layer was visualized, the surgeon introduced one finger into the incision and performed blunt dissection to separate the peritoneal layer from the abdominal wall, under constant visual control via the umbilical port [20]. Once the extraperitoneal space was formed, a $15-\mathrm{mm}$ trocar was inserted and gas was insufflated into the extraperitoneal space at a pressure of 12 to $14 \mathrm{mmH} \mathrm{g}[20,21]$. A $5-\mathrm{mm}$ and $10-\mathrm{mm}$ trocar was placed at the midaxillary line, and another $5-\mathrm{mm}$ trocar was placed if needed; four to five trocars were placed in total. Posteriorly, peritoneal marsupialization was performed with a $2-$ to $3-\mathrm{cm}$ incision to prevent formation of lymph cysts was performed to prevent the formation of lymph cysts. Lymphadenectomy were performed before hysterectomy in extraperitoneal laparoscopy.

The operating time was recorded from skin incision to closure, and included all procedures performed in each group. We also recorded the blood loss volumes for the three procedures. Intra-operative and postoperative complications were studied. Postoperative complications were defined as any complications occurring within 90 days after surgery.

All the surgeons in our department were well trained and skilled in both laparotomy and minimally invasive procedures, and all procedures were done by the same experienced gynecologic oncologists. Histopathologic diagnosis was made and reviewed by 2 experienced pathologists.

\section{Statistical analysis}

The patients' age and body mass index (BMI) were compared using one-way ANOVA post hoc test, surgical stage, number of harvested para-aortic lymph nodes, surgical time, estimated blood loss, and hospital stay were compared using the Mann-Whitney $U$ test in each paired group. Fisher's exact test was used to compare categorical variables between groups. A $p$ value of $<0.05$ was considered statistically significant. SPSS and MedCalc version 11.1.2.0 (MedCalc Software, Ostend, Belgium) was used for all statistical analysis.

\section{Results}

We reviewed the data of 176 patients who underwent primary surgical staging treatment for endometrial cancer. The patients were divided into a transperitoneal laparoscopic para-aortic lymphadenectomy group (group $\mathrm{T}, n=21$ ), laparotomic para-aortic lymphadenectomy group (group L, $n=135$ ), and extraperitoneal laparoscopic para-aortic lymphadenectomy group (group E, $n$ $=20$ ). View from the left side during the extraperitoneal approach and position of each trocar placed is presented in Fig. 1.

The patients' characteristics are summarized in Table 1. The patients' median age at surgery was similar in Group T, Group L, and Group E (52, 54, and 55 years, respectively; all comparisons, $p>0.05)$. The median BMI was also similar in group $\mathrm{T}, \mathrm{L}$, and $\mathrm{E}(24.35,24.22$, and 25.45 $\mathrm{kgm}^{2}$, respectively; all comparisons, $p>0.05$ ). The most common histological type was endometrioid adenocarcinoma in all groups, and grade 1 was the most common tumor grade in all three groups. The FIGO stage was also comparable in the three groups (stages I and II vs stages III and IV, all comparisons, $p>0.05$ ), and stage IA was the most common stage.

The numbers of para-aortic nodes harvested via the different procedures are presented in Table 2. The median number of para-aortic lymph nodes was significantly higher in group $\mathrm{E}$ than in groups $\mathrm{T}$ and group $\mathrm{L}(9.5,5$, and 6 , respectively; $p=0.004$ and $p=0.0004$, respectively). There was no significant difference between group $\mathrm{T}$ and $\mathrm{L}(p=0.581)$. Patients in group $\mathrm{L}$ had more positive aortic nodes than patients in groups $\mathrm{T}$ and $\mathrm{E}(30,0$, and 1 respectively). All patients in group $\mathrm{E}$ underwent successful dissections to the RV level, and $71.43 \%$ and 94.07\% of the patients in groups $\mathrm{T}$ and $\mathrm{L}$, respectively. The rate of dissection to the RV level was significantly higher in groups $\mathrm{L}$ and $\mathrm{E}$ than in group $\mathrm{T}(p=0.0043$ and $p=0.02$, respectively), but the difference between groups $\mathrm{L}$ and $\mathrm{E}$ was not statistically significant $(p=0.597)$. After limiting the count of removed lymph nodes to the group of patients who have dissected the para-aortic region up to the RV level, median number of harvested para-aortic node is 7, 6, and 9.5 in groups $T, L$, and $E$, respectively. Group $\mathrm{E}$ harvest more node than group L $(p=0.0005)$, but not significantly different with group T ( $p=0.082)$.

Perioperative and postoperative details are shown in Table 3. The median operation time was significantly shorter in group L than in groups $\mathrm{T}$ and $\mathrm{E}$ (96 min, 174 $\mathrm{min}$, and $233 \mathrm{~min}$, respectively; $p<0.0001$ ). The difference between groups $\mathrm{T}$ and $\mathrm{E}$ was also significant $(p=$ $0.001)$.

The estimated blood loss volumes were higher in group $\mathrm{L}$ than in groups $\mathrm{T}$ and $\mathrm{E}(200 \mathrm{ml}, 100 \mathrm{ml}$, and $142.5 \mathrm{ml}$, respectively; all comparisons, $p<0.001$ ), but difference 

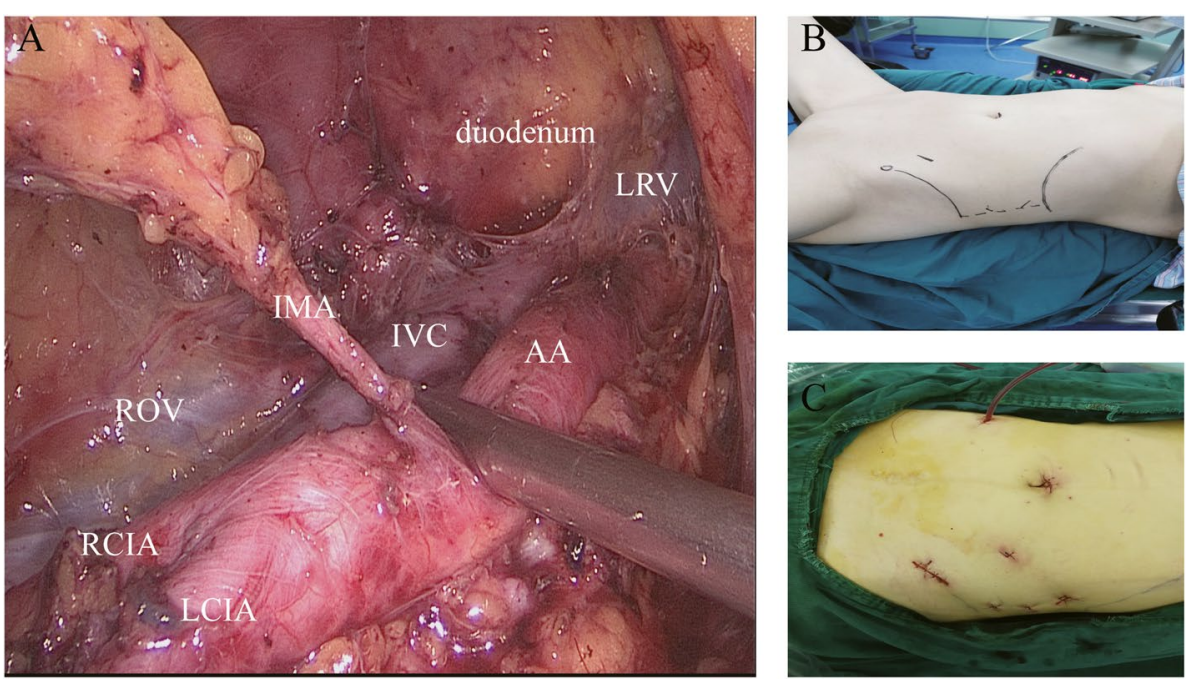

Fig. 1 A View from the left side during the extraperitoneal approach, with the duodenum and left renal vein (LRV) as the roof of the dissection cavity. The inferior mesenteric artery (IMA) emanates from the abdominal aorta (AA), which accompanied the inferior vena cava (IVC). B Incision position for extraperitoneal laparoscopy

between groups $\mathrm{T}$ and group $\mathrm{E}$ was not statistically significant $(p>0.05)$.

The median length of hospital stay was significantly longer in group $\mathrm{L}$ than in groups $\mathrm{T}$ and $\mathrm{E}(6,5$, and 6 respectively; all comparisons, $p<0.001)$. The length of hospital stay was similar in groups $\mathrm{T}$ and $\mathrm{E}(p=0.078)$.

Urinary injury was the most common intraoperative complication in groups $\mathrm{T}$ and $\mathrm{L}$, whereas no patients sustained a urinary injury in group E. Patients in Group L developed the most postoperative complications, namely paralytic ileus $(0.74 \%)$, asymptomatic lymphocele formation $(7.4 \%)$, and lymphedema $(0.74 \%)$. Only one patient was converted from group $\mathrm{E}$ to group $\mathrm{T}$ because of peritoneal leakage, and this patient was analyzed as part of group T.

\section{Discussion}

Thorough staging of endometrial carcinoma not only results in accurate documentation of disease spread, but is also a therapeutic intervention [13]. Minimally invasive techniques have recently been proven safe alternatives for surgical staging, with less morbidity and quick recovery. The extraperitoneal laparoscopic lymphadenectomy approach provides equally favorable outcomes, especially regarding reaching the supramesenteric lymph nodes [5]. The upper limit of para-aortic lymphadenectomy must be the left renal vein because many studies have shown that clinically early endometrial carcinoma may have positive infrarenal nodes [12, 22, 23]. For this reason, our team routinely used the renal vein as the upper margin for lymphadenectomy.
The key finding of our study is that after comparing the transperitoneal, laparotomic, and extraperitoneal approaches, the extraperitoneal laparoscopic approach was most satisfactory for staging endometrial carcinoma, especially regarding para-aortic lymphadenectomy.

This study also showed that extraperitoneal laparoscopic para-aortic lymphadenectomy harvested higher numbers of para-aortic nodes than the other two approaches. This might be because of the left-side extraperitoneal technique provides easier access to the left aortic nodes, which contains $63 \%$ of all aortic nodes $[15,16]$.The extraperitoneal approach allows improved access to the left aortic lymph nodes, especially to the challenging supramesenteric nodal group without bowel interfering. A previous study suggested harvesting 5.3 to 21 aortic nodes. We harvested a median of 9.5 para-aortic lymph nodes in group E, 5 in group T, and 6 in group L. Pakish et al. [24] reported a mean of 5 nodes harvested using the transperitoneal approach and 10 nodes using the extraperitoneal approach. The authors also indicated that extraperitoneal laparoscopy harvested significantly higher numbers of para-aortic lymph nodes than the transperitoneal approach. Dowdy et al. [20] found that the total number of harvested para-aortic lymph nodes was not significantly different between extraperitoneal laparoscopy and laparotomy. Although there was no difference in the rate of dissection to the RV level between group $L$ and group $E$, these two approaches were significantly different in number of nodes harvest. Therefore, we believe that difference 
Table 1 Patients characteristics

\begin{tabular}{|c|c|c|c|c|}
\hline Patient characteristics & $\begin{array}{l}\text { group T } \\
n=21\end{array}$ & $\begin{array}{l}\text { groupL } \\
n=135\end{array}$ & $\begin{array}{l}\text { group E } \\
n=20\end{array}$ & $P$ value \\
\hline \multicolumn{5}{|l|}{ Age at surgery,yrs } \\
\hline median(range) & $52(39-70)$ & $54(32-75)$ & $55(41-69)$ & \multirow[t]{7}{*}{ All $p>0.05$} \\
\hline BMI,kg/m2 (median,range) & $24.35(16.9-32.51)$ & $24.22(16.41-50.78)$ & $25.45(21.19-32.51)$ & \\
\hline$<18, \mathrm{n}(\%)$ & $1(4.76 \%)$ & $1(0.74 \%)$ & $0(0 \%)$ & \\
\hline $18-25, n(\%)$ & 13(61.9\%) & $76(56.3 \%)$ & $8(40 \%)$ & \\
\hline $25-30, n(\%)$ & $6(28.57 \%)$ & $45(33.33 \%)$ & $10(50 \%)$ & \\
\hline $30-35, n(\%)$ & $1(4.76 \%)$ & $11(8.15 \%)$ & $2(10 \%)$ & \\
\hline$>35, \mathrm{n}(\%)$ & $0(0 \%)$ & $2(1.48 \%)$ & $0(0 \%)$ & \\
\hline \multicolumn{5}{|l|}{ Surgical stage } \\
\hline IA & $14(66.67 \%)$ & $90(66.67 \%)$ & $12(60 \%)$ & \multirow{9}{*}{$\begin{array}{l}\text { stage I and II vs stage III and IV all } p> \\
0.05\end{array}$} \\
\hline $\mathrm{IB}$ & $3(14.29 \%)$ & $14(10.37 \%)$ & $5(25 \%)$ & \\
\hline$\|$ & $2(9.52 \%)$ & $10(7.4 \%)$ & $1(5 \%)$ & \\
\hline$\| I I A$ & $2(9.52)$ & $3(2.22 \%)$ & $0(0 \%)$ & \\
\hline$\| I \mathrm{~B}$ & $0(0 \%)$ & $1(0.74 \%)$ & $0(0 \%)$ & \\
\hline$\| I \mid C 1$ & $0(0 \%)$ & $11(8.15 \%)$ & $1(5 \%)$ & \\
\hline$\| I \mid C 2$ & $0(0 \%)$ & $4(2.96 \%)$ & $1(5 \%)$ & \\
\hline IVA & $0(0 \%)$ & $0(0 \%)$ & $0(0 \%)$ & \\
\hline IVB & $0(0 \%)$ & $(2.96 \%)$ & $0(0 \%)$ & \\
\hline \multicolumn{5}{|l|}{ Histologic grade (G) } \\
\hline G1 & $9(42.86 \%)$ & $55(40.74 \%)$ & $9(45 \%)$ & \multirow[t]{4}{*}{ distribution of tumor grades, All $p>0.05$} \\
\hline G2 & $9(42.86 \%)$ & $44(32.59 \%)$ & $6(30 \%)$ & \\
\hline G3 & $1(4.76 \%)$ & 19(9.63\%) & $3(15 \%)$ & \\
\hline UPSC & $0(0 \%)$ & $8(5.93 \%)$ & $1(5 \%)$ & \\
\hline CCC & $0(0 \%)$ & $7(5.19 \%)$ & $0(0 \%)$ & \multirow[t]{5}{*}{ histopathological types, $p>0.05$} \\
\hline MMMT & $0(0 \%)$ & $0(0 \%)$ & $0(0 \%)$ & \\
\hline Gx & $2(9.52 \%)$ & $0(0 \%)$ & $0(0 \%)$ & \\
\hline Mixed epithelial carcinoma & $0(0 \%)$ & $1(0.74 \%)$ & $0(0 \%)$ & \\
\hline Dedifferentiated carcinoma & $0(0 \%)$ & $10.74 \%)$ & $1(5 \%)$ & \\
\hline
\end{tabular}

Footnote: BMI body max index, UPSC uterineserous carcinoma, CCC clear cell carcinoma, MMMT malignant mullerian mixed tumor

Table 2 Patients characteristics of para-aortic node dissection via different procedure

\begin{tabular}{|c|c|c|c|c|}
\hline & $\begin{array}{l}\text { groupT } \\
n=21\end{array}$ & $\begin{array}{l}\text { groupL } \\
n=135\end{array}$ & $\begin{array}{l}\text { groupE } \\
n=20\end{array}$ & \\
\hline \multicolumn{4}{|l|}{ No. of para-aortic lymph nodes } & \multirow[b]{2}{*}{$\begin{array}{l}\text { group } T \text { vs } \\
\text { group } L, P= \\
0.581, \text { group } T \text { vs } \\
\text { group } E \\
P=0.004, \text { group } \\
L \text { vs group } E, P= \\
0.0004\end{array}$} \\
\hline median(range) & $5(1-21)$ & $6(1-19)$ & $9.5(5-29)$ & \\
\hline positive aortic nodes & $0(0 \%)$ & $30(22.22 \%)$ & $1(5 \%)$ & \\
\hline cases with positive aortic nodes, no.(\%) & $0(0 \%)$ & $6(4.44 \%)$ & $1(5 \%)$ & \\
\hline cases with dissection to RV level & $15(71.43 \%)$ & 127(94.07\%) & $20(100 \%)$ & $\begin{array}{l}\text { group } T \text { vs } \\
\text { group } L, P= \\
0.0043, \text { group } T \\
\text { vs group } E \\
P=0.02, \text { group } L \\
\text { vs group } E, P= \\
0.597\end{array}$ \\
\hline
\end{tabular}


Table 3 Perioperative and postoperative characteristics

\begin{tabular}{|c|c|c|c|c|}
\hline & $\begin{array}{l}\text { group T } \\
n=21\end{array}$ & $\begin{array}{l}\text { group L } \\
n=135\end{array}$ & $\begin{array}{l}\text { group E } \\
n=20\end{array}$ & $P$ Value \\
\hline Surgical time, $\min ^{*}$ & & & & ${ }^{*}$ group T vs group $L, P<0.0001$ \\
\hline median(range) & 174(93-275) & $96(51-212)$ & 233.5(145-309) & $\begin{array}{l}{ }^{*} \text { group T vs group } E, P=0.001 \\
{ }^{*} \text { group } L \text { vs group } E, P<0.0001\end{array}$ \\
\hline \multicolumn{5}{|c|}{ intraoperative complications,no(\%) } \\
\hline urinary injury & $1(4.76 \%)$ & $2(1.48 \%)$ & 0 & \\
\hline $\begin{array}{l}\text { estimated blood loss, } \mathrm{ml}^{\#} \\
\text { median(range) }\end{array}$ & $100(50-200)$ & $200(50-1000)$ & $142.5(50-300)$ & \multirow{3}{*}{$\begin{array}{l}\text { \#group T vs group } L, P<0.0001 \\
\text { \#group T vs group } E, P>0.05 \\
\text { \#group } L \text { vs group } E, P=0.0086\end{array}$} \\
\hline Blood transfusion (unit) & & & & \\
\hline mean(range) & $0(0 \%)$ & $0.17(0-4)$ & 0 & \\
\hline \multicolumn{5}{|l|}{ Surgical procedure } \\
\hline hysterectomy & 19(90.48\%) & $117(86.67 \%)$ & 19(95\%) & \\
\hline radical hysterectomy & $2(9.52 \%)$ & 18(13.33\%) & $0(0 \%)$ & \\
\hline omentectomy & $0(0 \%)$ & $23(17.04 \%)$ & $3(15 \%)$ & \\
\hline appendectomy & $0(0 \%)$ & $5(3.7 \%)$ & $1(5 \%)$ & \\
\hline CRS & $0(0 \%)$ & $1(0.74 \%)$ & $0(0 \%)$ & \\
\hline \multicolumn{5}{|l|}{ hospital stay,days* } \\
\hline median(range) & $5(3-11)$ & $6(4-21)$ & $6(5-7)$ & \multirow{5}{*}{$\begin{array}{l}\text { *group T vs group } L, P<0.0001 \\
\text { *group T vs group } E, P=0.0781 \\
\text { *group L vs group } E, P<0.0001\end{array}$} \\
\hline postoperative complications & & & & \\
\hline paralutic ileus & $0(0 \%)$ & $1(0.74 \%)$ & $0(0 \%)$ & \\
\hline asymptomatic lymphocele & $0(0 \%)$ & $10(7.4 \%)$ & $0(0 \%)$ & \\
\hline lymphedema & $0(0 \%)$ & $1(0.74 \%)$ & $0(0 \%)$ & \\
\hline
\end{tabular}

of removed lymph nodes numbers not only related to the level of lymph node dissection, but also related to the technique.

Removing more inframesenteric nodes significantly increases the likelihood of finding cancer, as does increasing the numbers of dissected infrarenal nodes [13]. Although we harvested more para-aortic lymph nodes in group $\mathrm{E}$, the percentage of positive nodes was higher in group L. This result might be explained by the larger portion of grade 3 tumors and non-endometrial carcinomas in group L, including papillary serous carcinoma, clear cell carcinoma, and malignant mixed mesodermal tumors, which are considered high-risk and more likely to metastasize to lymph nodes. Recently, increasingly more studies have been showing that lymphadenectomy does not benefit patients with grades 1 and 2 endometrioid lesions with myometrial invasion of $\leq 50 \%$ and a primary diameter of $\leq 2 \mathrm{~cm}$ [25]. Thus, performing more limited dissection of nodes or sentinel nodes, or even harvesting nodes might be safe in low-risk patients [26-28]. SLN (sentinel lymph node) mapping in early-staged EC has been demonstrated to be safe and accurate [28]. Low rate of lymph node metastasis in our results also support this, and limited node dissection might be adopted in our further work.

Time-consuming was a major disadvantage of the extraperitoneal approach in our study. Examination of the intraoperative outcomes revealed no significant difference in the total operative time between the groups in a previous study [5], similar to our results. The operative time in group E was 30 min longer than that in Group $\mathrm{T}$ and 130 min longer than that in group L. As reported previously, the extraperitoneal laparoscopic approach was associated with significantly shorter operative times for lymphadenectomy, whereas the total operative times were not different between the two groups [5]. The longer time might be related to the time required to prepare the retroperitoneal space. Previous studies showed that the total operative time with the extraperitoneal approach ranged from 200 to $339.5 \mathrm{~min}$ [1, 18, 24], and our results were similar. Surgery in both group $\mathrm{T}$ and group $\mathrm{E}$ required more time than with laparotomy, which might reflect surgical skill.

The estimated blood loss volumes were lowest in group $\mathrm{T}$, and the length of hospital stay was shortest in group $\mathrm{E}$. Group L had significantly higher blood loss volumes and significantly longer hospital stays. These findings are consistent with the Gynecologic Oncology Group's recommendation to perform minimally invasive approaches for endometrial cancer because of less blood loss and shorter length of hospital stay [7].

The most frequently reported postoperative complications after lymph node dissection are lymphocele and lymphedema [17], and paralytic ileus is also not uncommon. In group $E$, we routinely performed peritoneal marsupialization to prevent the formation of lymph cysts. We found that group $\mathrm{E}$ had few complications 
and low failure rates; only one patient required conversion to transperitoneal laparoscopy, similar to previous studies [20, 29].

Our study has several limitations; the first limitation is the retrospective nature of the clinical data and the single-center design. Second, the sample size in group $\mathrm{E}$ was small, and the small number of patients with a BMI of > $35 \mathrm{~kg} / \mathrm{m}^{2}$ limited the BMI-correlated subgroup analysis. Therefore, our results are limited to patients with a BMI of $<35 \mathrm{~kg} / \mathrm{m}^{2}$. Additionally, because we began performing extraperitoneal laparoscopy (group E) only within 3 years of this study, we did not analyze overall survival in each group. As most of the patients in our study were stage 1A, whether these results are applicable to patients with higher stages of disease still need further study.

\section{Conclusion}

Our study showed that endometrial carcinoma staging via the extraperitoneal laparoscopic approach resulted in higher numbers of dissected para-aortic lymph nodes, longer surgical time, fewer intraoperative and postoperative complications, and shorter hospital stays than the laparotomy approach. The extraperitoneal laparoscopic approach should be considered for surgical staging of endometrial carcinoma.

\section{Supplementary Information}

The online version contains supplementary material available at https://doi. org/10.1186/s12957-021-02416-x.

\section{Additional file 1.}

\section{Acknowledgements}

Not applicable

\section{Authors' contributions}

Conception and design: CXJ;WXH. Data Acquisition: XLF, WH, and JXZ. Data analysis and interpretation: HXT and YHJ. Drafting the article: ZW. Revising it critically for important intellectual content: ZW and CXJ. Final approval of the version to be published: CXJ and WXH. Agreement to be accountable for all aspects of the work: $\mathrm{WXH}$. All authors have read and approved the manuscript.

\section{Funding}

Wei Zhang is supported by the National Natural Science Foundation of China (81602270). The service fee of the researchers in our study was supported by this funding.

\section{Availability of data and materials}

The dataset supporting the conclusions of this article is included within the article and its additional file.

\section{Declarations}

\section{Ethics approval and consent to participate}

Approval to review the patients' medical records and pathological reports was obtained from the institutional review board of Fudan University Shanghai Cancer Center, Shanghai, China. Written informed consent was obtained from all patients.

\section{Consent for publication}

Written informed consent was obtained from the patient for publication and accompanying images. A copy of the written consent is available for review by the Editor of this journal.

\section{Competing interests}

The authors declare that they have no competing interests.

Received: 7 April 2021 Accepted: 2 October 2021

Published online: 07 November 2021

\section{References}

1. Diaz-Feijoo B, Correa-Paris A, Perez-Benavente A, Franco-Camps S, Sanchez-Iglesias JL, Cabrera S, et al. Prospective randomized trial comparing transperitoneal versus extraperitoneal laparoscopic aortic lymphadenectomy for surgical staging of endometrial and ovarian cancer: the STELLA trial. Ann Surg Oncol. 2016;23:2966-74.

2. Walker JL, Piedmonte MR, Spirtos NM, Eisenkop SM, Schlaerth JB, Mannel RS, et al. Laparoscopy compared with laparotomy for comprehensive surgical staging of uterine cancer: Gynecologic Oncology Group Study LAP2. J Clin Oncol. 2009;27:5331-6.

3. Vasilev SA, McGonigle KF. Extraperitoneal laparoscopic paraaortic lymph node dissection: development of a technique. J Laparoendosc Surg. 1995:5:85-90.

4. Querleu D, Dargent D, Ansquer Y, Leblanc E, Narducci F. Extraperitoneal endosurgical aortic and common iliac dissection in the staging of bulky or advanced cervical carcinomas. Cancer. 2000:88:1883-91.

5. Prodromidou A, Machairas N, Spartalis E, Kostakis ID, lavazzo C, Moris D, et al. Transperitoneal versus extraperitoneal laparoscopic lymphadenectomy for gynecological malignancies: a systematic review and metaanalysis. Anticancer Res. 2018;38:4677-81.

6. Ferron G, De Santiago J, Querleu D, Martinez A, Angeles MA, Boulet $B$, et al. Left lateral endosurgical extraperitoneal total hysterectomy with para-aortic and pelvic lymphadenectomy: a novel approach for the obese patient with endometrial cancer. J Minim Invasive Gynecol. 2018;25:730-6

7. Narducci F, Lambaudie E, Mautone D, Hudry D, Bresson L, Leblanc E. Extraperitoneal para-aortic lymphadenectomy by robot-assisted laparoscopy in gynecologic oncology: preliminary experience and advantages and limitations. Int J Gynecol Cancer. 2015:25:1494-502.

8. Soliman PT, Frumovitz M, Spannuth W, Greer MJ, Sharma S, Schmeler $\mathrm{KM}$, et al. Lymphadenectomy during endometrial cancer staging: practice patterns among gynecologic oncologists. Gynecol Oncol. 2010:119:291-4.

9. Zhang W, Zhang J, Yang J, Xue H, Cao D, Huang H, et al. The role of magnetic resonance imaging in pretreatment evaluation of early-stage cervical cancer. Int J Gynecol Cancer. 2014;24:1292-8.

10. Franchi $\mathrm{M}$, Garzon $\mathrm{S}$, Zorzato $\mathrm{PC}$, Laganà AS, Casarin J, Locantore L, et al, PET-CT scan in the preoperative workup of early stage intermediateand high-risk endometrial cancer. Minim Invasive Ther Allied Technol. 2020;29:232-9.

11. Ramirez PT, Jhingran A, Macapinlac HA, Euscher ED, Munsell MF, Coleman RL, et al. Laparoscopic extraperitoneal para-aortic lymphadenectomy in locally advanced cervical cancer: a prospective correlation of surgical findings with positron emission tomography/computed tomography findings. Cancer. 2011;117:1928-34.

12. Turan T, Yilmaz SS, Hizli D, Gundogdu B, Boran N, Tulunay G, et al. A prospective evaluation of lymphatic dissemination in endometrial cancer: is it adequate to perform lymph node dissection up to the inferior mesenteric artery? Int J Gynecol Cancer. 2011;21:864-9.

13. O'Hanlan KA, Sten MS, O'Holleran MS, Ford NN, Struck DM, McCutcheon SP. Infrarenal lymphadenectomy for gynecological malignancies: two laparoscopic approaches. Gynecol Oncol. 2015;139:330-7.

14. Todo Y, Kato H, Minobe S, Okamoto K, Suzuki Y, Sudo S, et al. Initial failure site according to primary treatment with or without para-aortic lymphadenectomy in endometrial cancer. Gynecol Oncol. 2011:121:314-8.

15. Morice P, Joulie F, Camatte S, Atallah D, Rouzier R, Pautier P, et al. Lymph node involvement in epithelial ovarian cancer: analysis of 276 pelvic and 
paraaortic lymphadenectomies and surgical implications. J Am Coll Surg. 2003;197:198-205.

16. Michel G, Morice P, Castaigne D, Leblanc M, Rey A, Duvillard P. Lymphatic spread in stage Ib and II cervical carcinoma: anatomy and surgical implications. Obstet Gynecol. 1998;91:360-3.

17. Morales S, Zapardiel I, Grabowski JP, Hernandez A, Diestro MD, GonzalezBenitez C, et al. Surgical outcome of extraperitoneal paraaortic lymph node dissections compared with transperitoneal approach in gynecologic cancer patients. J Minim Invasive Gynecol. 2013;20:611-5.

18. Akladios C, Ronzino V, Schrot-Sanyan S, Afors K, Fernandes R, Baldauf $\mathrm{J}$, et al. Comparison between transperitoneal and extraperitoneal laparoscopic paraaortic lymphadenectomy in gynecologic malignancies. J Minim Invasive Gynecol. 2015;22:268-74.

19. Narducci F, Lambaudie E, Houvenaeghel G, Collinet P, Leblanc E. Early experience of robotic-assisted laparoscopy for extraperitoneal paraaortic lymphadenectomy up to the left renal vein. Gynecol Oncol. 2009;115:172-4.

20. Dowdy SC, Aletti G, Cliby WA, Podratz KC, Mariani A. Extra-peritoneal laparoscopic para-aortic lymphadenectomy--a prospective cohort study of 293 patients with endometrial cancer. Gynecol Oncol. 2008;111:418-24.

21. Gorostidi M, Diaz-Feijoo B. Concerns about robotic extraperitoneal para-aortic lymphadenectomy as isolated procedure: is it worth it? Int J Gynecol Cancer. 2015;25:192.

22. Scribner DR Jr, Walker JL, Johnson GA, McMeekin SD, Gold MA, Mannel RS. Laparoscopic pelvic and paraaortic lymph node dissection: analysis of the first 100 cases. Gynecol Oncol. 2001;82:498-503.

23. Burke TW, Levenback C, Tornos C, Morris M, Wharton JT, Gershenson DM. Intraabdominal lymphatic mapping to direct selective pelvic and paraaortic lymphadenectomy in women with high-risk endometrial cancer: results of a pilot study. Gynecol Oncol. 1996;62:169-73.

24. Pakish J, Soliman PT, Frumovitz M, Westin SN, Schmeler KM, Reis RD, et al. A comparison of extraperitoneal versus transperitoneal laparoscopic or robotic para-aortic lymphadenectomy for staging of endometrial carcinoma. Gynecol Oncol. 2014;132:366-71.

25. Mariani A, Dowdy SC, Cliby WA, Gostout BS, Jones MB, Wilson TO, et al. Prospective assessment of lymphatic dissemination in endometrial cancer: a paradigm shift in surgical staging. Gynecol Oncol. 2008;109:11-8.

26. Bogani G, Murgia F, Ditto A, Raspagliesi F. Sentinel node mapping vs. lymphadenectomy in endometrial cancer: A systematic review and metaanalysis. Gynecol Oncol. 2019;153:676-83.

27. Rossi EC, Kowalski LD, Scalici J, Cantrell L, Schuler K, Hanna RK, et al. A comparison of sentinel lymph node biopsy to lymphadenectomy for endometrial cancer staging (FIRES trial): a multicentre, prospective, cohort study. Lancet Oncol. 2017;18:384-92.

28. Zorzato PC, Bosco M, Franchi MP, Mariani A, Cianci S, Garzon S, et al. Sentinel lymph-node for endometrial cancer treatment: review of literature. Minerva Med. 2021;112(1):70-80.

29. Diaz-Feijoo B, Gil-Ibanez B, Perez-Benavente A, Martinez-Gomez X, Colas E, Sanchez-lglesias JL, et al. Comparison of robotic-assisted vs conventional laparoscopy for extraperitoneal paraaortic lymphadenectomy. Gynecol Oncol. 2014;132:98-101.

\section{Publisher's Note}

Springer Nature remains neutral with regard to jurisdictional claims in published maps and institutional affiliations.
Ready to submit your research? Choose BMC and benefit from:

- fast, convenient online submission

- thorough peer review by experienced researchers in your field

- rapid publication on acceptance

- support for research data, including large and complex data types

- gold Open Access which fosters wider collaboration and increased citations

- maximum visibility for your research: over $100 \mathrm{M}$ website views per year

At BMC, research is always in progress.

Learn more biomedcentral.com/submissions 